International Review of Research in Open and Distributed Learning Volume 16, Number 4

October - 2015

\title{
Editorial: Leadership in Open and Distance Learning Notes
}

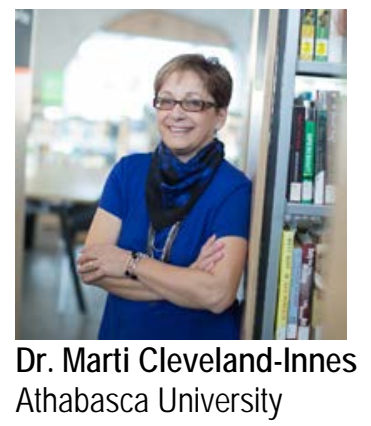

This issue's Leadership Notes section contains two discussion pieces about education transformation. The first by Tom Brown provides a timely response to Barber, Donnelly, and Rizvi's (2013) discussion of the impact of changing technology on higher education. For Brown, the avalanche of change created by technology is accompanied by an incumbent avalanche of change in teaching and learning. While Brown does not speak to leadership processes, he provides vision and direction as we push forward. We can claim that leadership is a necessary but insufficient condition for change in higher education; clear direction makes leading down new pathways much easier.

In the second piece, Orr and Cleveland-Innes discuss a new process for leading down new pathways in their discussion of Appreciative Leadership. In support of the education innovation Brown refers to, Orr and Cleveland-Innes describe the relationship between Appreciative Inquiry, organizational transformation, and the necessary leadership for this relationship to unfold. To accomplish Brown's suggested move to navigationalism, leaders will have to support a change in thinking before asking for a change in behaviour or activity. Contrasted with other leadership theories, Appreciative Leaders are described as those who maintain an ongoing quest of seeing, and making explicit, the positive potential in both the staff and organization as transformation occurs.

These two discussion pieces offer the opportunity to reflect on leadership and direction as education continues to transform to new ways of designing and delivering teaching and learning. 
Editorial: Leadership in Open and Distance

Cleveland-Innes

(c) Cleveland-Innes

\section{Athabasca University $\mathbf{I}$}

(c) 